\title{
Ordered mesoporous oxide for thin film microbatteries with enhanced lithium storage
}

\author{
Gregorio F. Ortiz ${ }^{* a}$, Ángel Berenguer-Murcia ${ }^{\mathrm{b}}$, Marta Cabello ${ }^{\mathrm{a}}$, Diego Cazorla-Amorós ${ }^{\mathrm{b}}$ \\ and José L. Tirado ${ }^{\mathrm{a}}$ \\ ${ }^{a}$ Laboratorio de Química Inorgánica, Universidad de Córdoba, Edificio Marie Curie, Campus de \\ Rabanales, 14071 Córdoba, Spain \\ ${ }^{b}$ Instituto Universitario de Materiales, Departamento de Química Inorgánica, Universidad de Alicante, \\ Ap. 99 - 03080 Alicante, Spain
}

*Corresponding author, email: q72maorg@uco.es

Tel. and Fax.: +34 957218637 


\begin{abstract}
A 3D mesoporous $\mathrm{TiO}_{2}$ material with well-developed mesostructure is prepared in the form of a binderless thin $(100 \mathrm{~nm})$ film and studied as potential candidate for the negative electrode in lithium micro-batteries. By appropriate thermal treatments, the selected crystal structure (anatase, rutile, or amorphous), and micro-/mesostructure of the materials was obtained. An extended plateau with at about $0.75 \mathrm{~V}$ was found for an X-ray amorphous $\mathrm{TiO}_{2}$ sample $\left(400{ }^{\circ} \mathrm{C}\right)$ which can be tentatively assigned to the irreversible formation of cubic- $-\mathrm{Li}_{2} \mathrm{Ti}_{2} \mathrm{O}_{4}$. The effects of voltage window and prelithiation treatment improved first cycle reversibility up to $86 \%$ and capacity retention of $90 \%$ over 100 cycles. This study highlights the flexibility of the potential window to which the electrode can operate. Maximum capacity values over 100 cycles of 470 $\mu \mathrm{A} \mathrm{h} \mathrm{cm}{ }^{-2} \mu \mathrm{m}^{-1}$ and $177 \mu \mathrm{A} \mathrm{h} \mathrm{cm}{ }^{-2} \mu \mathrm{m}^{-1}$ are obtained for voltage ranges of $0.1-2.6 \mathrm{~V}$ and $1.0-2.6 \mathrm{~V}$, respectively. The observed values are between 6 and 2 times higher than those obtained for films with $600 \mathrm{~nm}\left(80 \mu \mathrm{Ah} \mathrm{cm}^{-2} \mu \mathrm{m}^{-1}\right)$ and $900 \mathrm{~nm}\left(92 \mu \mathrm{Ah} \mathrm{cm} \mathrm{cm}^{-}\right.$ $\left.{ }^{2} \mu \mathrm{m}^{-1}\right)$ lengths. This indicates that $100 \mathrm{~nm}$ thin $\mathrm{TiO}_{2}$ films with high accessibility show finite-length type diffusion which is interesting for this particular application.
\end{abstract}

Keywords: Ordered mesoporous $\mathrm{TiO}_{2}$, binderless electrodes, $\mathrm{Li}$-ion microbatteries, improved lithium storage 


\section{Introduction}

The excellent performance of rechargeable lithium-ion batteries (LIBs) has enabled the wireless revolution of electronic devices such as computers, digital cameras or cell phones that has transformed global communications. Nowadays the performance of LIBs is dominated by the chemistry design of electrode materials [1,2]. For highpower applications of LIBs, it is recommendable to find anode materials alternative to graphite due to its low capacity at high rates and low reaction potential (close to $0.1 \mathrm{~V}$ vs. $\left.\mathrm{Li}^{+} / \mathrm{Li}^{0}\right)[3,4]$. Therefore, the scientific community is still exploring potential candidates. Upon reaching this goal, safety in batteries could be achieved. For instance, metal oxides have represented an interesting class of anode materials due to their high capacities [4]. Among metal oxide materials, $\mathrm{TiO}_{2}$ has been widely considered because of several aspects such as intercalation-based reaction with lithium, high stability, nontoxicity and abundance among others. From a structural point of view titanium dioxide displays a variety of crystalline polymorphs including anatase, rutile, $\mathrm{TiO}_{2}-\mathrm{B}$, brookite, ramsdellite $(\mathrm{R})$, hollandite $(\mathrm{H})$, columbite and baddeleyite. Among them, only anatase, rutile brookite and $\mathrm{TiO}_{2}-\mathrm{B}$ have been tested for LIB applications [5-8]. Also, $\mathrm{TiO}_{2}$ presenting X-ray amorphous phase have been readily investigated exhibiting an excellent capacity and long cycling life, but still suffers from high irreversibility in the first cycle and needs of a wide voltage window to deliver reasonable capacity (170 $\left.200 \mathrm{~mA} \mathrm{~h} \mathrm{~g}^{-1}\right)$.

The main drawback of the $\mathrm{TiO}_{2}$ polymorphs is the poor Li ion diffusion and accompanying electrons in its bulk form which restricts the full material utilization electrochemically [9-11]. To improve the intrinsic (charge/ion) transport properties, $\mathrm{TiO}_{2}$ polymorphs must be prepared in nanostructure that could enhance the intercalation properties. Numerous nanostructured $\mathrm{TiO}_{2}$ materials, such as nanotubes, nanofibers, 
nanowires, and nanoparticles, were designed to improve its electrochemical performance for LIBs [12-16]. Irrespective of their poor electrical conductivity, it has been demonstrated that a layer of self-organized $\mathrm{TiO}_{2}$ nanotubes $\left(\mathrm{ntTiO}_{2}\right)$ is useful for alternative Li-ion batteries without conducting binders [6,7]. Indeed, for microelectronic industry it is desirable the use of thin film materials without additives since could reduce about a $20 \%$ of their size and weight. For instance $n t \mathrm{TiO}_{2}$ layers of 900 and 600 $\mathrm{nm}$ of nanotube length growth directly from Ti current collectors exhibited volumetric capacity of about 80 and $90 \mu \mathrm{A} \mathrm{h} \mathrm{cm}{ }^{-2} \mu \mathrm{m}^{-1}$, respectively [6,7].

Brinker and co-workers [17] developed a simple and straightforward approach to fabricate thin films based on phenomenon known as Evaporation-Induced SelfAssembly. By a careful control of the synthesis conditions, as well as of the composition of the precursor solution, the relative humidity during the solvent evaporation stage or the thermal treatment to which the resulting thin film is submitted to, the composition of the nanostructured coatings and their porous structure may be controlled [18]. From this perspective, the simplest approach would be to use a wellestablished methodology such as dip-coating to transfer a $\mathrm{TiO}_{2}$ film with a thickness under $100 \mathrm{~nm}$ to a substrate which could be employed as current collector [19].

The objective of our work is to prepare homogeneous thin film 3Dmesoestructures of $\mathrm{TiO}_{2}$ with thickness of $100 \mathrm{~nm}$ on $\mathrm{Ti}$ current collectors. Experimental results in Li cells demonstrated an improved performance of $100 \mathrm{~nm}$ thick film in terms of high capacity, long cycle life, and high rate capability in microbatteries. The poor conductive properties of titania commonly requires de use of carbon additives to facilitate electrical contact between nanoparticles, as well as binders to achieve the necessary mechanical stability of the electrodes. These additives decrease the overall electrode capacity and impose rigidity which impedes potential applications where 
flexible electrodes are required, such as the origami battery concept [20]. The electrode design developed in this work facilitates efficient electron transport while eliminating the need for binders and conductive carbon additives without jeopardizing their stability on long-term cycling. Thus, these materials are presented as interesting candidate as anode materials for Li-ion microbatteries (LIMBs).

\section{Experimental}

2.1. Materials and reagents: Titanium plates $(1 \times 1 \mathrm{~cm})$ with a purity of $99.6+\%$ were purchased from Goodfellow. Triblock copolymers pluronic P123 (EO20PO70EO20, M=5800) and F127 (EO106PO70EO106, M=12600) were kindly donated by BASF chemical company and used as templates. Titanium tetraisopropoxide (TTIP) and titanium tetrachloride $\left(\mathrm{TiCl}_{4}\right)$ were purchased from Sigma Aldrich and used as Titanium sources. All reagents were used as received with no further purification.

2.2. Thin film preparation: Mesoporous $\mathrm{TiO}_{2}$ thin films were grown on flat $\mathrm{Ti}$ plates by two different routes found in the literature which give rise to 3D hexagonal ( $P 6_{3} / m m c$ symmetry) [21] and cubic (Im-3m symmetry) [22] thin films, respectively. All Ti samples were wiped clean with a cloth impregnated with absolute EtOH to remove any dust or particles from the surface of the plates.

In synthetic protocol (1), $1.05 \mathrm{~g}$ of Pluronic P123 were added to $16.21 \mathrm{~g}$ of absolute ethanol. The solution was stirred until completely clear, and then $4.03 \mathrm{~g}$ of concentrated (37\%) $\mathrm{HCl}$ were added dropwise. To the resulting mixture, $5.70 \mathrm{~g}$ of TTIP were added dropwise, giving the final solution the following molar composition: 1 TTIP:0.01 P123:17.6 EtOH:1.9 HCl:7.2 $\mathrm{H}_{2} \mathrm{O}$. 
In synthetic protocol (2), $0.51 \mathrm{~g}$ of Pluronic F127 were dissolved in $14.71 \mathrm{~g}$ of absolute ethanol by gentle heating and under strong stirring. To this clear homogenous solution $880 \mu \mathrm{L}$ of $\mathrm{TiCl}_{4}$ were added very slowly and under vigorous stirring to give a solution with the following molar composition: $1 \mathrm{TiCl}_{4}: 40 \mathrm{EtOH}: 0.005 \mathrm{~F} 127$.

Titania films were produced by dip-coating at a withdrawal speed of $1 \mathrm{~mm} \cdot \mathrm{s}^{-1}$. The Titanium substrates were rinsed with absolute EtOH prior to deposition. The relative humidity $(\mathrm{RH})$ during dip-coating was set at 50\%. After deposition, films were aged at $\mathrm{RH} 50 \%$ for $24 \mathrm{~h}$. Calcination of the films was performed either in a vacuum furnace at $300^{\circ} \mathrm{C}$ under high vacuum conditions for 1 hour or in a muffle furnace at either 400,550 , or $700^{\circ} \mathrm{C}$ for 1 hour. In all experiments, the heating rate was $1{ }^{\circ} \mathrm{C} /$ minute.

2.3. Characterization: $X$-ray diffraction $(\mathrm{XRD})$ patterns were recorded at room

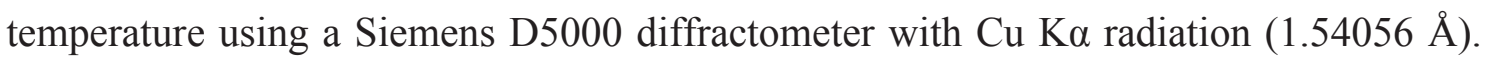
The synthesized thin films were characterized by transmission electron microscopy (TEM) using a JEOL JEM-2010 high-tilt instrument operating at $200 \mathrm{kV}$ with a structural spatial resolution of $0.5 \mathrm{~nm}$. The samples were scratched off from the $\mathrm{Ti}$ surface and recovered with a droplet of ethanol. Then the suspensions were dropped gently on a holey amorphous carbon film on a $\mathrm{Cu}$ sample holder. The composition of the nanoparticles was measured by EDS coupled to the TEM equipment (OXFORD instruments model INCA Energy TEM100). The thin films were also characterized by Scanning Electron Microscopy (SEM) in a HITACHI S-3000N microscope and the thickness of the thin film prepared was studied. 
2.4. Electrochemical tests: The electrochemical performance of the mesoporous

\section{Results and discussions}

Fig. 1 shows the $\mathrm{X}$-ray diffraction pattern of the mesoporous $\mathrm{TiO}_{2}$ layers prepared on Ti plates at different temperatures using synthetic protocol (1) as a representative example of the samples analyzed in this study. A common characteristic of these XRD patterns is that they exhibit diffraction peaks ascribable to hexagonal $\mathrm{Ti}$ (PDF \# 05-0682, S.G.: P6 6 /mmc), the plate on which $\mathrm{TiO}_{2}$ was growth. An X-ray amorphous character is evidenced for samples heated at $300^{\circ} \mathrm{C}$ under vacuum since no peaks corresponding to crystalline $\mathrm{TiO}_{2}$ were observed. It is worth noting that our $\mathrm{Ti}$ plates showed the preferred growth orientation on (002), as shown by a comparison of the $002 / 101$ reflection intensity ratio with the database. When the films were thermally annealed at $400{ }^{\circ} \mathrm{C}$, no reflections ascribable to anatase $\mathrm{TiO}_{2}$ were observed (Fig. 1). 
This result is in apparent contradiction with the conversion of mesoporous $\mathrm{TiO}_{2}$ powders to the anatase structure at $400^{\circ} \mathrm{C}$ reported by Kubiak et al [23]. This particular difference is most probably a consequence of the low amount of active material deposited on the Ti current collector as compared with powder samples together with a low crystallite size in the films obtained at $400{ }^{\circ} \mathrm{C}$. The presence of anatase will be confirmed below by using electrochemical characterizations in the $\mathrm{Li}$ test cell. However, after annealing at $550{ }^{\circ} \mathrm{C}$ broad an low intense reflections are observed at about $25.3^{\circ}$ and $47.9^{\circ}$, which correspond to the 101 and 200 reflections of the anatase phase (JCPDS file \#21-1272), respectively. In addition, the films obtained at $550^{\circ} \mathrm{C}$ also showed low intensity reflections ascribable to rutile rutile (JCPDS file \#21-1276). A clearer view of the diffraction peaks is found for sample at $700{ }^{\circ} \mathrm{C}$ where new peaks with high intensity emerged, ascribable to the presence of high crystalline anatase and rutile phases, respectively (Fig. 1).

The development of the mesostructure of the thin films was verified by TEM. Fig. 2 shows the images of the as-synthesized thin films and those obtained after calcination in vacuum. The images clearly show that the prepared thin films showed a high quality mesostructure development with pore sizes between $4-5$ nanometers. Calcination of the samples did not alter the porous structure, which confirmed the stability of the grown $\mathrm{TiO}_{2}$ thin film resulting from the fine control of the synthesis and ageing conditions. Electron microscopy was also used in order to determine the thickness of the deposited thin film, which was estimated to be $100 \mathrm{~nm}$.

As the electrochemical storage based on lithium-ion intercalation represents one of the most technologically advanced forms of energy storage, it is mandatory to 
optimize the sample preparation and cycling conditions (e.g. voltage windows). The high value of the energy density and the versatility of the product in terms of fast charge/discharge and good capacity retention are the most studied parameters as well as the most important from a practical point of view. Briefly the Li insertion/deinsertion into the $\mathrm{TiO}_{2}$ can be written as follows:

$$
\mathrm{TiO}_{2}+\mathrm{xLi}^{+}+\mathrm{xe}^{-} \leftrightarrows \mathrm{Li}_{\mathrm{x}} \mathrm{TiO}_{2}
$$

Theoretically, the insertion of $0.5 \mathrm{Li}$ into the crystalline anatase phase gives a capacity value of $168 \mathrm{~mA} \mathrm{~h} \mathrm{~g}^{-1}$ [24], and for $1.0 \mathrm{Li}$ per Ti it reaches $336 \mathrm{~mA} \mathrm{~h} \mathrm{~g}^{-1}$ or $1,297 \mathrm{~mA} \mathrm{~h} \mathrm{~cm}{ }^{-3}\left(\delta=3.86 \mathrm{~g} \mathrm{~cm}^{-3}\right)$. The electrochemical insertion of lithium ions takes place through a two-phase equilibrium of a Li-poor (tetragonal) and a Li-rich (orthorhombic) phase [25]. The orthorhombic phase formation is due to the accommodation of donated charge ( $\mathrm{Li}$ donates an electron to the lattice) in localized Ti-d orbitals. Titanium ions in the anatase structure are arranged in a tetragonal configuration with $\left[\mathrm{TiO}_{6}\right]$ octahedral units. The distortion of the $\left[\mathrm{TiO}_{6}\right]$ octahedral unit is greater in the anatase than in the rutile phase. For Li-ion storage, the anatase $\mathrm{TiO}_{2}$ phase is favorable because Li-ions readily penetrate into the structure and exhibit thermodynamic stability $[26,27]$.

Figures $3-7$ show the electrochemical properties for binderless 3D mesoporous

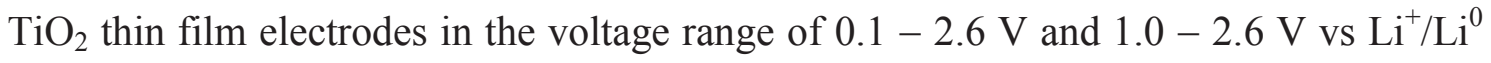
for synthesis protocol (1). The results for synthesis protocol (2) showed a poorer performance (not shown). This difference can be ascribed to the cubic (Im-3m symmetry) of the later thin films. The higher number of neighbor pores in $P 6_{3} m m c$ hexagonal packing may account for a better connectivity and lithium diffusivity. Another possible explanation would be that the two samples show different $\mathrm{TiO}_{2}$ 
crystallite size, which in turn would affect the performance of the resulting electrode although this difference was not observable by X-ray diffraction or TEM. Figures $3-7$ include the voltage profiles during the first 5 cycles, cycling performance and rate capabilities. The areal capacity is normally used to quantify the capacity for Li-ion microbatteries, and the volumetric capacity can also be deduced by taking into consideration the thickness of the film. To have comparative results with the literature, the current density used in this work is $5 \mu \mathrm{A} \mathrm{cm}{ }^{-2}$ which is the same as those used for others $\mathrm{TiO}_{2}$ thin film with 600 and $900 \mathrm{~nm}$ of thickness in previous reports [6,7]. All the samples thermally annealed at 400,550 and $700{ }^{\circ} \mathrm{C}$ exhibit a discharge voltage plateau at $1.76 \mathrm{~V}$ and a charge voltage plateau at $1.92 \mathrm{~V}$, which correspond to the intercalation/de-intercalation of $\mathrm{Li}$ ions from the interstitial octahedral sites of anatase $\mathrm{TiO}_{2}[6,7,28]$. However, a different reaction mechanism for the sample activated at $300{ }^{\circ} \mathrm{C}$ under vacuum was observed, which is typical of amorphous $\mathrm{TiO}_{2}$ electrodes with a continuous decay of the potential from 3 to $0.1 \mathrm{~V}$.

The amount of inserted $\mathrm{Li}^{+}$in the $\mathrm{TiO}_{2}$ is dependent on whether the crystal structure is anatase, rutile or amorphous, as well as on the microstructure [3-6]. For the $\mathrm{TiO}_{2}$ treated at $400{ }^{\circ} \mathrm{C}$ the total capacity in the first discharge was $258.5 \mu \mathrm{A} \mathrm{h} \mathrm{cm}{ }^{-2}(\sim$ $\left.2585 \mu \mathrm{A} \mathrm{h} \mathrm{cm} \mathrm{hm}^{-1}\right)$ and the reversible capacity in the first cycle is $106 \mu \mathrm{A} \mathrm{h} \mathrm{cm}^{-2}(\sim$ $1060 \mu \mathrm{A} \mathrm{h} \mathrm{cm}{ }^{-2} \mu \mathrm{m}^{-1}$ ), resulting in an efficiency of $41 \%$ from first to second cycle, and $44 \%$ over 150 cycles $\left(470 \mu \mathrm{A} \mathrm{h} \mathrm{cm}{ }^{-2} \mu \mathrm{m}^{-1}\right.$ Fig. $\left.4 \mathrm{a}-\mathrm{b}\right)$. Our 3D architecture $\mathrm{TiO}_{2}$ film can deliver a capacity of $470 \mu \mathrm{A} \mathrm{h} \mathrm{cm}{ }^{-2} \mu \mathrm{m}^{-1}$ over 150 cycles, and this value is about six order of magnitude higher as compared to layers of self-organized $\mathrm{TiO}_{2}$ nanotubes with $600 \mathrm{~nm}\left(80 \mu \mathrm{Ah} \mathrm{cm}^{-2} \mu \mathrm{m}^{-1}\right)$ and $900 \mathrm{~nm}\left(92 \mu \mathrm{Ah} \mathrm{cm}^{-2} \mu \mathrm{m}^{-1}\right)$ lengths [6,7]. For $\mathrm{TiO}_{2}$ annealed at $550{ }^{\circ} \mathrm{C}$ the total capacity in the first discharge is $105 \mu \mathrm{A} \mathrm{h} \mathrm{cm}{ }^{-2}(\sim 1050 \mu \mathrm{A}$ $\left.\mathrm{h} \mathrm{cm}^{-2} \mu \mathrm{m}^{-1}\right)$ and the reversible capacity in first cycle is $57.5 \mu \mathrm{A} \mathrm{h} \mathrm{cm}^{-2}(\sim 575 \mu \mathrm{A} \mathrm{h} \mathrm{cm}-$ 
${ }^{2} \mu \mathrm{m}^{-1}$ ), resulting in an efficiency of $54 \%$ from first to second cycle, and $28 \%$ over 105 cycles. For $\mathrm{TiO}_{2}$ at $700{ }^{\circ} \mathrm{C}$ the total capacity in the first discharge is $91.2 \mu \mathrm{A} \mathrm{h} \mathrm{cm}{ }^{-2}$ $\left(\sim 912 \mu \mathrm{A} \mathrm{h} \mathrm{cm}^{-2} \mu \mathrm{m}^{-1}\right)$ and the reversible capacity in first cycle is $36.6 \mu \mathrm{A} \mathrm{h} \mathrm{cm}^{-2}(\sim$ $366 \mu \mathrm{A} \mathrm{h} \mathrm{cm}{ }^{-2} \mu \mathrm{m}^{-1}$ ), resulting in an efficiency of $40 \%$ from first to second cycle, and $38 \%$ over 100 cycles. Achieving reversible reactions in the intercalation zone of anatase is possible in these films with $100 \mathrm{~nm}$ thickness due to the fact that their mesostructure (i.e. porous structure) is composed of interconnected pores of $4-5$ nanometers in size within a 3D lattice. The mesostructure facilitates the diffusion of $\mathrm{Li}$ ions throughout the entire volume of the thin film, which clearly shows the importance of the correct development of the thin film mesostructure. Nevertheless, the wide voltage window $(0.1-2.6 \mathrm{~V})$ provides very high irreversibility (Fig. 3). In general, the efficiency from first to second cycle is very low ca. $35-37 \%$ (Table 1). Lithium intercalation into trapped sites, side reactions of lithium with some $\mathrm{H}_{2} \mathrm{O}$ molecules adsorbed on the $\mathrm{TiO}_{2}[6,7,29]$, the formation of a very thin disordered layer at the electrode surface [9] and poor intrinsic electronic conductivity [30] are possible origins for the irreversible capacity. Gao et al.[31], reported the first direct evidence of new reaction mechanisms in amorphous $\mathrm{TiO}_{2}$ nanomaterials, indicating that the lithiation started with the valence reduction of $\mathrm{Ti}^{4+}$ to $\mathrm{Ti}^{3+}$ leading to a $\mathrm{Li}_{\mathrm{x}} \mathrm{TiO}_{2}$ intercalation compound. However, in this recent paper further intercalation of $\mathrm{Li}$ ions in $\mathrm{TiO}_{2}$ triggered a transformation from amorphous to a crystalline phase identified as $\mathrm{Li}_{2} \mathrm{Ti}_{2} \mathrm{O}_{4}$ with cubic structure [31]. On the basis of these observations, in our electrode prepared at $400^{\circ} \mathrm{C}$, which gave an X-ray amorphous character, a plateau at $0.75 \mathrm{~V}$ is observed that may be assigned to the formation of very small crystallites of $\mathrm{Li}_{2} \mathrm{Ti}_{2} \mathrm{O}_{4}$. This contribution is solely observed in the first discharge and consequently is not reversible 
upon further charge/discharge (Fig. 3). This latter affirmation is in agreement with the observation of Xiong et al. [32], where they demonstrated the formation of a new crystalline material with a high degree of symmetry when cycling at potentials below 1.1 $\mathrm{V}$ which gave an irreversible crystallization process. In the crystallized product $\mathrm{Ti}$ and Li are randomly distributed among all octahedral sites in a nearly ideal cubic closed packed oxygen array. The resulting nanocrystalline product allows fast charge and discharge.

Up to now, little attention has been paid to avoiding the initial irreversibility in $\mathrm{TiO}_{2}$ by using pre-lithiation treatment. Fig. $5-6$ shows a comparison of the electrochemical performance with and without pre-lithiation treatment using new $1.0-$ 2.6 V voltage ranges. Thus, efficiency from first to second cycle was increased to 52, 50 and $51 \%$ for samples treated at 400,550 and $700{ }^{\circ} \mathrm{C}$, respectively. The pre-lithiated electrode showed much better cycling efficiency of 86,75 and $85 \%$ for samples at 400 , 550 and $700{ }^{\circ} \mathrm{C}$, respectively. A comparison between the cyclability of mesoporous electrodes with and without pre-lithiation treatment is depicted in Figure 7. The obtained capacities are lowered due to strict voltage limitation while the narrower voltage window allowed minimizing irreversibility as compared to the previous discussion. The best electrochemical behavior corresponds to electrodes thermally annealed at $400{ }^{\circ} \mathrm{C}$, which precisely gave typical behavior of an anatase-based reaction. About $86 \%$ of efficiency from first to second cycle with $19.65 \mu \mathrm{Ah} \mathrm{cm}^{-2}(196.5$ $\left.\mu \mathrm{A} \mathrm{h} \mathrm{cm}{ }^{-2} \mu \mathrm{m}^{-1}\right)$ and $90 \%$ of capacity retention over 100 cycles $\left(177 \mu \mathrm{Ah} \mathrm{cm}^{-2} \mu \mathrm{m}^{-1}\right)$ are achieved. Capacities presented here for a 3D binderless mesoporous $\mathrm{TiO}_{2}$ thin film are really attractive in terms of high kinetics and energy density when compared with other thin layer-based electrodes, for example, a titania nanotube layer grown on Ti foils 
(13.5 and $13.2 \mu \mathrm{Ah} \mathrm{cm}^{-2} \mu \mathrm{m}^{-1}$ recorded in $1^{\text {st }}$ reversible and over 100 cycles, respectively), on Ti foams (63.3 and $66.7 \mu \mathrm{Ah} \mathrm{cm}^{-2} \mu \mathrm{m}^{-1}$ recorded in $1^{\text {st }}$ reversible and over 100 cycles, respectively) [33] or even comparing with highly ordered anodic $\mathrm{TiO}_{2}$ nanotube arrays $\left(26.7 \mu \mathrm{Ah} \mathrm{cm}^{-2} \mu \mathrm{m}^{-1}\right)$ [34] or a layer of $\mathrm{ntTiO}_{2}$ containing submicron $\mathrm{Co}_{3} \mathrm{O}_{4}$ particles $\left(137.3 \mu \mathrm{Ah} \mathrm{cm}^{-2} \mu \mathrm{m}^{-1}\right)$ [35] suggesting that the novel architecture electrode presented here can be a potential candidate for the fabrication of nanostructured thin film microbatteries. To see further details of capacity value of different electrodes see Table 1.

In order to achieve extended cycle life in advanced electrodes the stability of the binderless $\mathrm{TiO}_{2}$ thin films was studied. Ex-situ analysis of cycled electrodes prepared at 300 and $700{ }^{\circ} \mathrm{C}$ after 125 and 100 cycles at $3.0 \mathrm{~V}$, respectively, were performed by HRTEM and SEM (Fig. 8). The mesoporous structure disappeared in both samples as deduced from HRTEM images from Fig. 7a,b. In this way, the pores seem to have disappeared and particles start coalescing. From TEM images it is observed that the agglomeration of particles is more evident for sample at $300{ }^{\circ} \mathrm{C}$ than for that of $700{ }^{\circ} \mathrm{C}$. Using ex-situ SEM images we have detected that the obtained material after long cycling displays agglomerates (Fig. 7c,d) composed of almost spherical particles. The sample at $300{ }^{\circ} \mathrm{C}$ seems to exhibit large number of particles forming agglomerates where the porous structure seems to disappear, while the sample at $700{ }^{\circ} \mathrm{C}$ seems to be formed smaller particle agglomerates (about $20 \mathrm{~nm}$ ) and some porous organization is observed with an average pore of 60-70 $\mathrm{nm}$. This rearrangement does not compromise cycle life and capacity retention. Irrespective of the above discussed morphological changes, the initial cohesion and accessibility to the electrolyte of the initial domains in 
the mesoporous structure are preserved, thus allowing extended cycling at moderate rates.

The half-cell using $100 \mathrm{~nm} \mathrm{TiO}_{2}$ layer is able to provide about $75 \%$ of theoretical capacity in $900 \mathrm{~s}$ (3 C). Moreover, an ideal full 3-D, Li-ion battery combining this electrode with a $4.8 \mathrm{~V}$ cathode (e.g. $\mathrm{LiNi}_{0.5} \mathrm{Mn}_{1.5} \mathrm{O}_{4}$ or $\mathrm{LiCoPO}_{4}$ ), could give a maximum energy density of $570 \mu \mathrm{Wh} \mathrm{cm}^{-2} \mu \mathrm{m}^{-1}$ and power density of $2.54 \mathrm{~mW}$ $\mathrm{cm}^{-2} \mu \mathrm{m}^{-1}$. The values presented here are very interesting from the point of view of microdevices applications, in which high energy densities are mandatory.

\section{Conclusions}

In order to improve the performance of mesoporous titania in lithium microbatteries, $\mathrm{TiO}_{2}$ films of ca. $100 \mathrm{~nm}$ with a well-defined hexagonally ordered porous structure were prepared directly on a titanium substrate. A strict control of voltage window and pre-lithiation treatment could drastically improve cycling efficiency. Maximum capacity values over 100 cycles of $470 \mu \mathrm{A} \mathrm{h} \mathrm{cm}{ }^{-2} \mu \mathrm{m}^{-1}$ and 177 $\mu \mathrm{A} \mathrm{h} \mathrm{cm}{ }^{-2} \mu \mathrm{m}^{-1}$ are obtained for voltage ranges of $0.1-2.6 \mathrm{~V}$ and $1.0-2.6 \mathrm{~V}$, respectively. For comparative purposes, films with $600 \mathrm{~nm}$ and $900 \mathrm{~nm}$ were also tested, although the capacity was significantly lower. Thus the porosity of this material allows the electrolyte reaching the complete mass of the electrode, while its mechanical stability allows tackling the use of polymer binder, and the electrical contact with the current collector makes unnecessary the use of carbon additives. All of these effects result in a higher overall areal and volumetric capacity than in other $\mathrm{TiO}_{2}$-based anode material previously considered for microbatteries. 


\section{Acknowledgements}

We thank the Spanish Ministry of Economy and Competitiveness and FEDER (MINECO Projects CTQ2012-31762 and MAT2011-22753) and Junta de Andalucía (FQM7206) for financial support. A.B.M. and GFO thank the MINECO for their Ramón y Cajal Fellowships (RyC 2009-03913 and 2010-05596, respectively). 


\section{References}

1. M. S. Whittingham, Chem. Rev. 104 (2004) 4271.

2. J. L. Tirado, Mater. Sci. Eng., R 40 (2003) 103.

3. H. H. Zheng,. Q. T. Qu, L. Zhang, G. Liu and V. S. Battalion, RSC Adv. 2 (2012) 4904.

4. H. B. Wu, J. S. Chen, H. H. Hng and X. W. Lou, Nanoscale 4 (2012) 2526.

5. G. Armstrong, A. R. Armstrong, J. Canales and P. G. Bruce, Electrochem. SolidState Lett. 9 (2006) A139.

6. G. F. Ortiz, I. Hanzu, P. Knauth, P. Lavela, J. L. Tirado and T. Djenizian, Chem. Mater. 21 (2009) 63.

7. G. F. Ortiz, I. Hanzu, T. Djenizian, P. Lavela, J. L. Tirado and P. Knauth, Electrochim. Acta 54 (2009) 4262.

8. B. Han, S. J. Kim, B. M. Hwang, S. B. Kim, and K. W. Park, J. Power Sources $222(2013) 225$.

9. K. Saravanan, K. Ananthanarayanan and P. Balaya, Energy Environ. Sci. 3 (2010) 939.

10. J. Hwang, C. Jo, K. Hur, J. Lim, S. Kim and J. Lee, J. Am. Chem. Soc., 2014, dx.doi.org/10.1021/ja5091172.

11. B. Zhao, C. Rui, S. Jiang, Y. Sha and Z. Shao, Electrochim. Acta 85 (2012) 636.

12. W. Xiong, Y. D. Wang and H. Xia, Mater. Technol. 28 (2013) 260.

13. J. R. González, R. Alcántara, F. Nacimiento, G. F. Ortiz, J. L. Tirado, E. Zhecheva and R. Stoyanova, J. Phys. Chem. C.116 (2012) 20182.

14. J. R. González, R. Alcántara, G. F. Ortiz, F. Nacimiento and J. L. Tirado, J. Electrochem. Soc. 160 (2013) A1390. 
15. J. C. You, W. J. Sheng, K. K. Huang, C. M. Hou, H. J. Yue, B. Hu, M. Wang, D. Wei, Q. W. Li, L. P. Zhao, W. Y. Dong, Z. G. Zhao and Y. J. Li, ACS Appl. Mater. Interfaces 5 (2013) 2278.

16. K. R. Alok, T. A. Ly, G. Jihyeon, M. Vinod, K. Jungwon, J. P. Baboo, S. Jinju and J. K. Song, Electrochim. Acta 90 (2013) 112.

17. C. J. Brinker, Y. Lu, A. Sellinger and H. Fan, Adv. Mater., 11 (1999) 579.

18. P.C.A. Alberius, K. L.Frindell, R. C. Hayward, E. J. Kramer, G. D. Stucky and B. F. Chmelka, Chem. Mater., 14 (2002) 3284.

19. E.V. Rebrov, A. Berenguer-Murcia, H. E. Skelton, B. F. G. Johnson, A. E. H. Wheatley and J. C. Schouten, Lab on a Chip, 9 (2009) 503.

20. Z. Song, T. Ma, R. Tang, Q. Cheng, X. Wang, D. Krishnaraju, R. Panat, C. K. Chan, H. Yu and H. Jiang, Nat. Commun. 2014, doi:10.1038/ ncomms4140.

21. H. Oveisi, X. Jiang, Y. Nemoto, A. Beitollahi and Y. Yamauchi, Microporous Mesoporous Mat., 139 (2011) 38.

22. L. Malfatti, M. G. Bellino, P. Innocenzi and G. J. A. A. Soler-Illia, Chem. Mater., 21 (2009) 2763.

23. P. Kubiak, J. Geserick, N. Hüsing and M. Wohlfahrt-Mehrens, J. Power Sources 175 (2008) 510.

24. L. Kavan, M. Grätzel, J. Rathousky and A. Zukal, J. Electrochem. Soc. 143 (1996) 394.

25. M. V. Koudriachova, N. M. Harrison and S. W. de Leeuw, Phys. Rev. B 65 (2002) 235423.

26. A. Stashans, S. Lunell and R. Bergstrom, Phys. Rev. B 53 (1996) 159.

27. R. Marchand, L. Brohan and M. Toumoux, Mater. Res. Bull. 15 (1980) 1129.

28. D. Deng, M. G. Kim, J. Y. Lee and J. Cho, Energ Environ Sci 2 (2009) 818. 
29. J. R. Li, Z. L. Tang and Z. T. Zhang, Electrochem. Solid-State Lett. 8 (2005) A316.

30. G. Armstrong, A. R. Armstrong, J. Canales and P. G. Bruce, J. Power Sources $143(2005) 501$.

31. Q. Gao, G. Meng, N. Anmin, M. Farzad, W. Chongmin, G. M. Odegard and R. Shahbazian-Yassar, Chem. Mater., 26 (2014) 1660.

32. H. Xiong, H. Yildirim, E. V. Shevchenko, V. B. Prakapenka, B. Koo, M. D. Slater, M. Balasubramanian, S. K. R. S. Sankaranarayanan, J. P. Greeley, S. Tepavcevic, N. M. Dimitrijevic, P. Podsiadlo, C. S. Johnson and T. Rajh, J. Phys. Chem. C 116 (2012) 3181.

33. Z. Bi, M. P. Paranthaman, P. A. Menchhofer, R. R. Dehoff, C. A. Bridges, M. Chi, B. Guo, X. G. Sun and S. Dai, J. Power Sources 22 (2013) 461.

34. W. Wei, G. Oltean, C. W. Tai, K. Edström, F. Björefors and L. Nyholm, J. Mater. Chem. A, 1 (2013) 8160.

35. N. A. Kyeremateng, C. Lebouin, P. Knauth, T. Djenizian, T. Electrochim. Acta 88 (2013) 814. 
Table 1. A comparison of the reversible and irreversible capacities obtained of the different mesoporous $\mathrm{TiO}_{2}$ electrodes. Note that "TC" is the total capacity in first discharge, "IC" is the irreversible capacity from first to second cycle, "RC" is the reversible capacity measured in second cycle, and "PL" is a pre-lithiated electrode.

\begin{tabular}{|c|c|c|c|c|c|}
\hline $\mathrm{TiO}_{2}$ & Voltage window & $\mathrm{TC} / \mu \mathrm{Ah} \mathrm{cm}^{-2}$ & $\mathrm{IC} / \mu \mathrm{Ah} \mathrm{cm}^{-2}$ & $\mathrm{RC} / \mu \mathrm{Ah} \mathrm{cm}^{-2}$ & Efficiency / \% \\
\hline $300^{\circ} \mathrm{C}$ & $0.1-2.6$ & 176 & 111 & 65 & 37 \\
\hline \multirow[t]{3}{*}{$400{ }^{\circ} \mathrm{C}$} & $0.1-2.6$ & 258.5 & 152.5 & 106 & 41 \\
\hline & $1.0-2.6$ & 59.9 & 28.8 & 31.1 & 52 \\
\hline & $1.0-2.6 \mathrm{PL}$ & 23 & 3.2 & 19.8 & 86 \\
\hline \multirow[t]{3}{*}{$550{ }^{\circ} \mathrm{C}$} & $0.1-2.6$ & 105 & 47.5 & 57.5 & 54 \\
\hline & $1.0-2.6$ & 42.2 & 20.94 & 21.26 & 50 \\
\hline & $1.0-2.6 \mathrm{PL}$ & 26.5 & 6.7 & 19.8 & 75 \\
\hline \multirow[t]{3}{*}{$700^{\circ} \mathrm{C}$} & $0.1-2.6$ & 91.2 & 54.6 & 36.6 & 40 \\
\hline & $1.0-2.6$ & 37.5 & 19.2 & 18.3 & 51 \\
\hline & $1.0-2.6 \mathrm{PL}$ & 15.6 & 2.3 & 13.3 & 85 \\
\hline
\end{tabular}




\section{Figure caption}

Figure 1. X-ray diffraction patterns of binderless mesoporous $\mathrm{TiO}_{2}$ thin films fabricated by protocol (1) on Ti plates $\left(0.5 \mathrm{~mm}\right.$ and $99.6 \%+$ purity) at $300{ }^{\circ} \mathrm{C}$ under vacuum and annealed at 400,550 and $700{ }^{\circ} \mathrm{C}$ in air, respectively.

Figure 2. HRTEM micrographs of (a) as-synthesized $\mathrm{TiO}_{2}$ thin film grown on $\mathrm{Ti}$ by synthesis protocol (1), (b) As-synthesized $\mathrm{TiO}_{2}$ thin film grown on $\mathrm{Ti}$ by synthesis protocol (2), (c) calcined $\mathrm{TiO}_{2}$ thin film $\left(300^{\circ} \mathrm{C}\right.$ under vacuum) grown on $\mathrm{Ti}$ by synthesis protocol (1), and (d) calcined $\mathrm{TiO}_{2}$ thin film $\left(300^{\circ} \mathrm{C}\right.$ under vacuum) grown on Ti by synthesis protocol (2).

Figure 3. Galvanostatic discharge/charge curves vs. capacity of binderless 3D mesoporous $\mathrm{TiO}_{2}$ thin films prepared by protocol (1) obtained at $300{ }^{\circ} \mathrm{C}$ under vacuum and annealed at 400,550 and $700{ }^{\circ} \mathrm{C}$ in air. Current rate: $5 \mu \mathrm{A} \mathrm{cm}{ }^{-2}$. Voltage limits: 2.6 $-0.1 \mathrm{~V}$.

Figure 4. Reversible capacity (areal and volumetric) vs. cycle number in lithium microcells for binderless $3 \mathrm{D}$ mesoporous $\mathrm{TiO}_{2}$ thin films prepared by synthesis protocol (1) obtained at $300{ }^{\circ} \mathrm{C}$ under vacuum and annealed at 400, 550 and $700{ }^{\circ} \mathrm{C}$ in air, respectively. Voltage window: $0.1-2.6 \mathrm{~V}$.

Figure 5. Galvanostatic discharge/charge curves vs. capacity of binderless 3D mesoporouns $\mathrm{TiO}_{2}$ thin films using $1.0-2.6 \mathrm{~V}$ voltage windows.

Figure 6. Effects of pre-lithiation treatment on lithium (de)-insertion on the binderless $3 \mathrm{D}$ nanoporous $\mathrm{TiO}_{2}$ thin film electrodes.

Figure 7. A comparison of electrochemical cycling performance of binderless 3D mesoporous $\mathrm{TiO}_{2}$ thin films electrodes with (a) and without pre-lithiation treatment (b). Voltage window: $1.0-2.6 \mathrm{~V}$.

Figure 8. Ex-situ HRTEM ( $a$ and $b$ ) and SEM (c and d) images of cycled electrodes prepared at 300 and $700{ }^{\circ} \mathrm{C}$ after 125 and 100 cycles at $3.0 \mathrm{~V}$, respectively. 


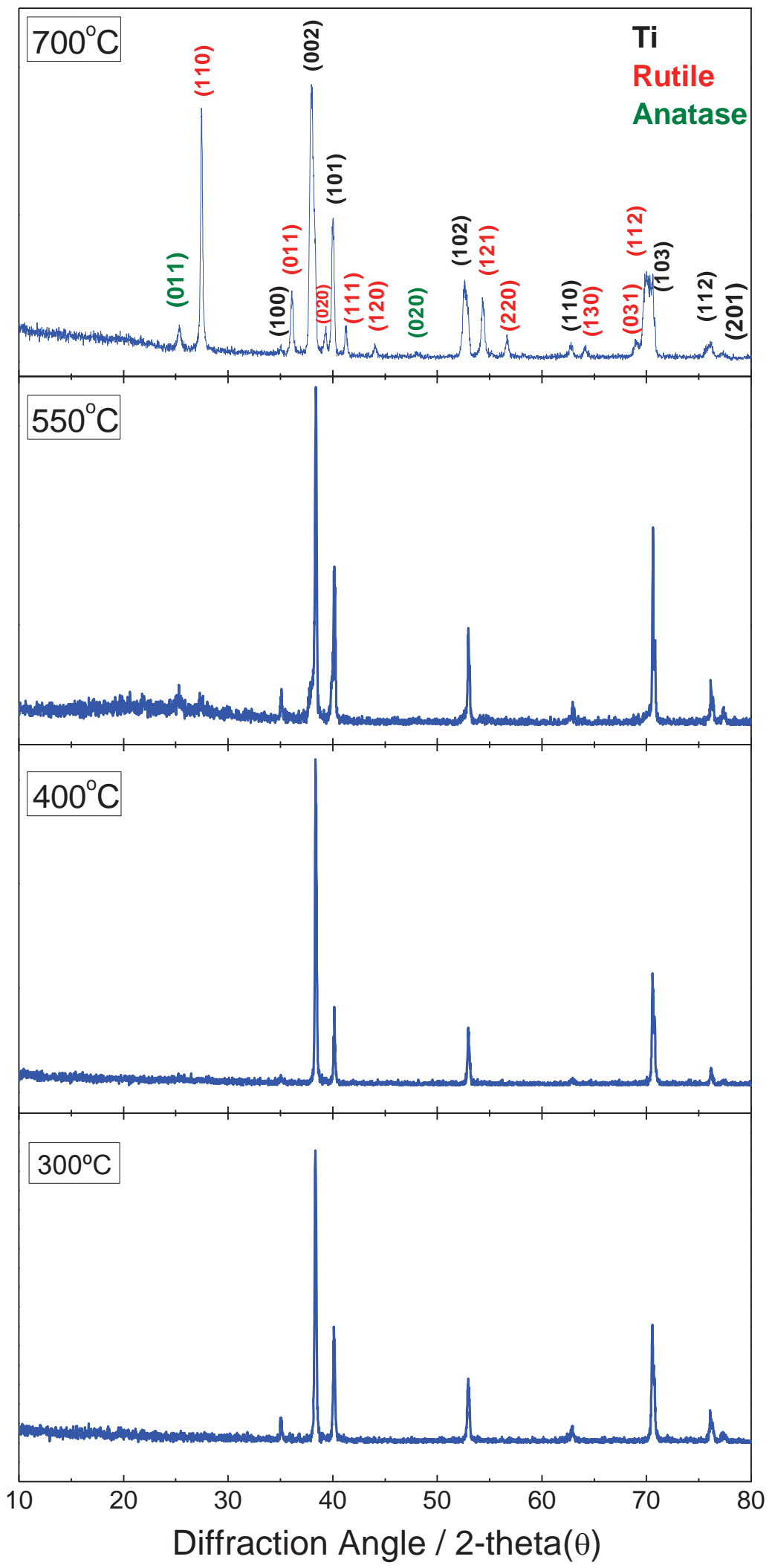

Figure 1. 

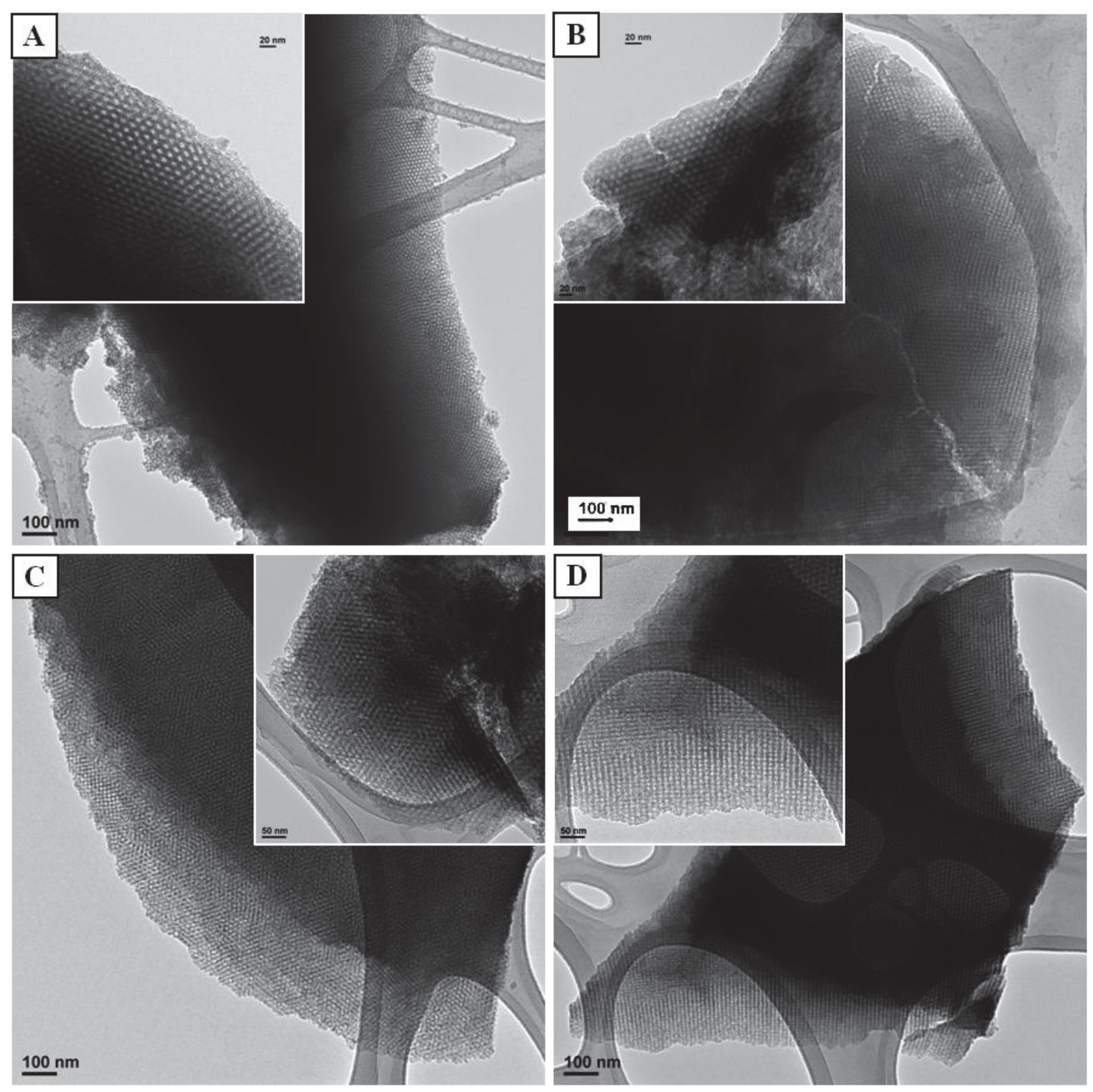

Figure 2. 
1

2

3

4

5
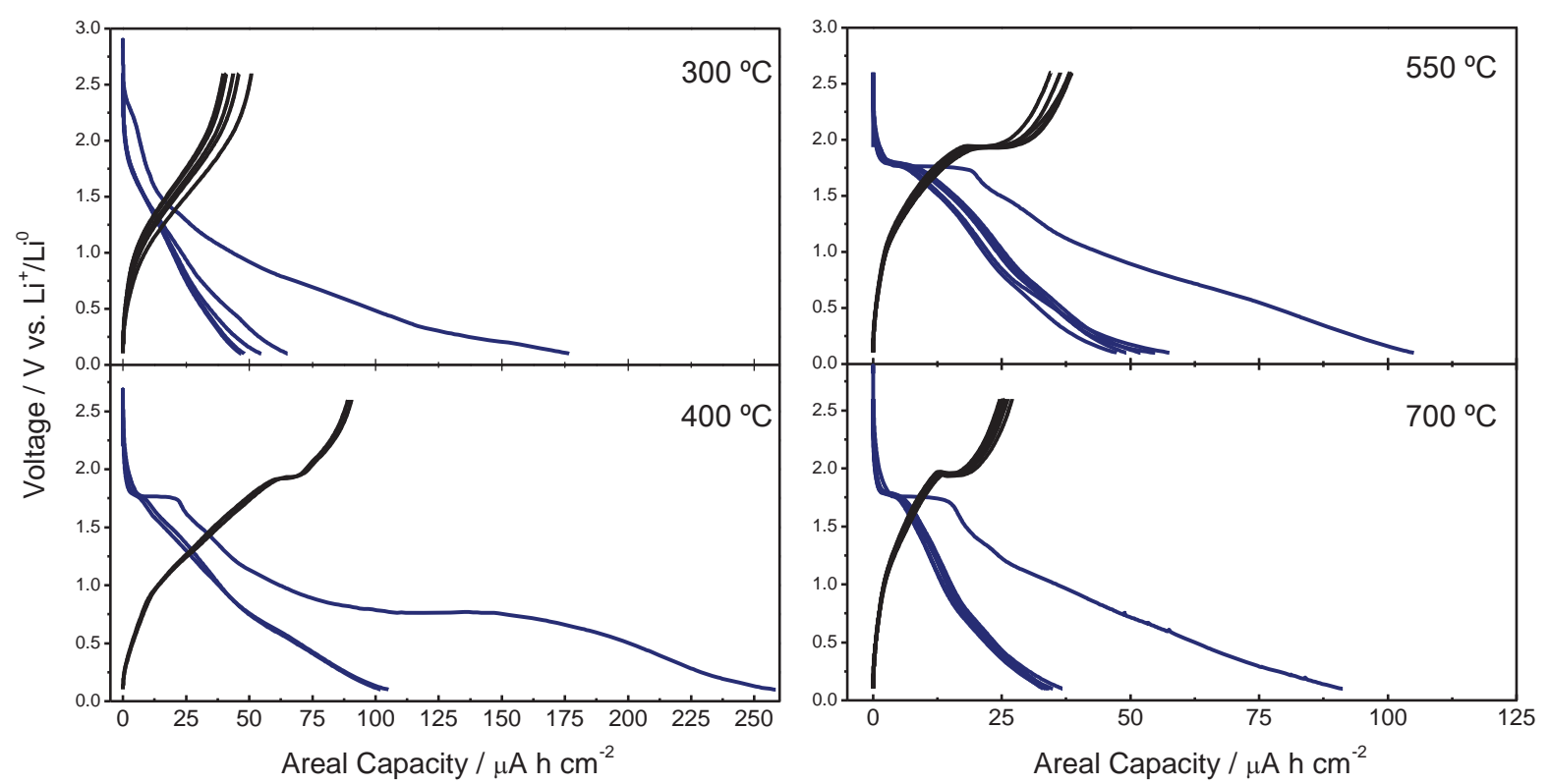

Figure 3. 
1

2

3

4

5

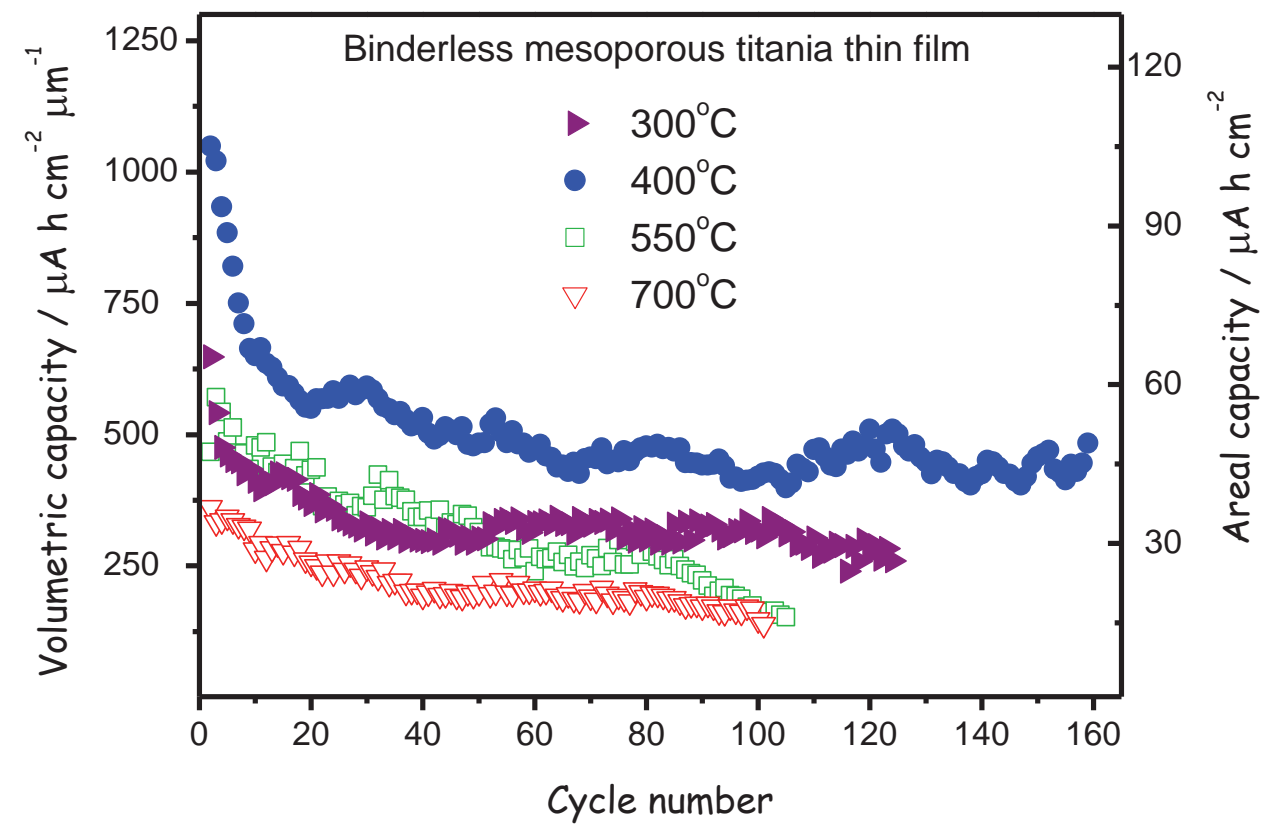

Figure 4. 


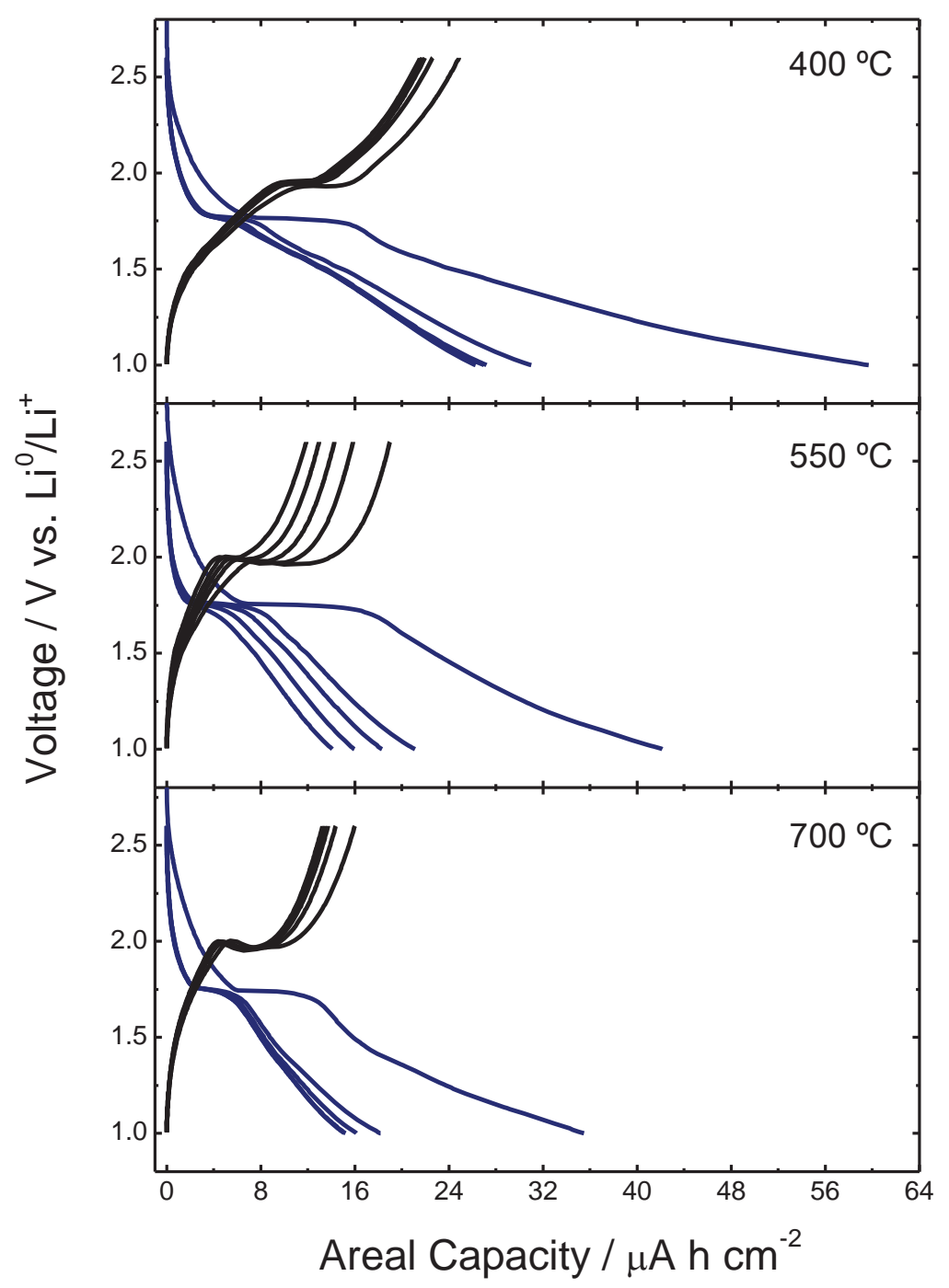

Figure 5. 


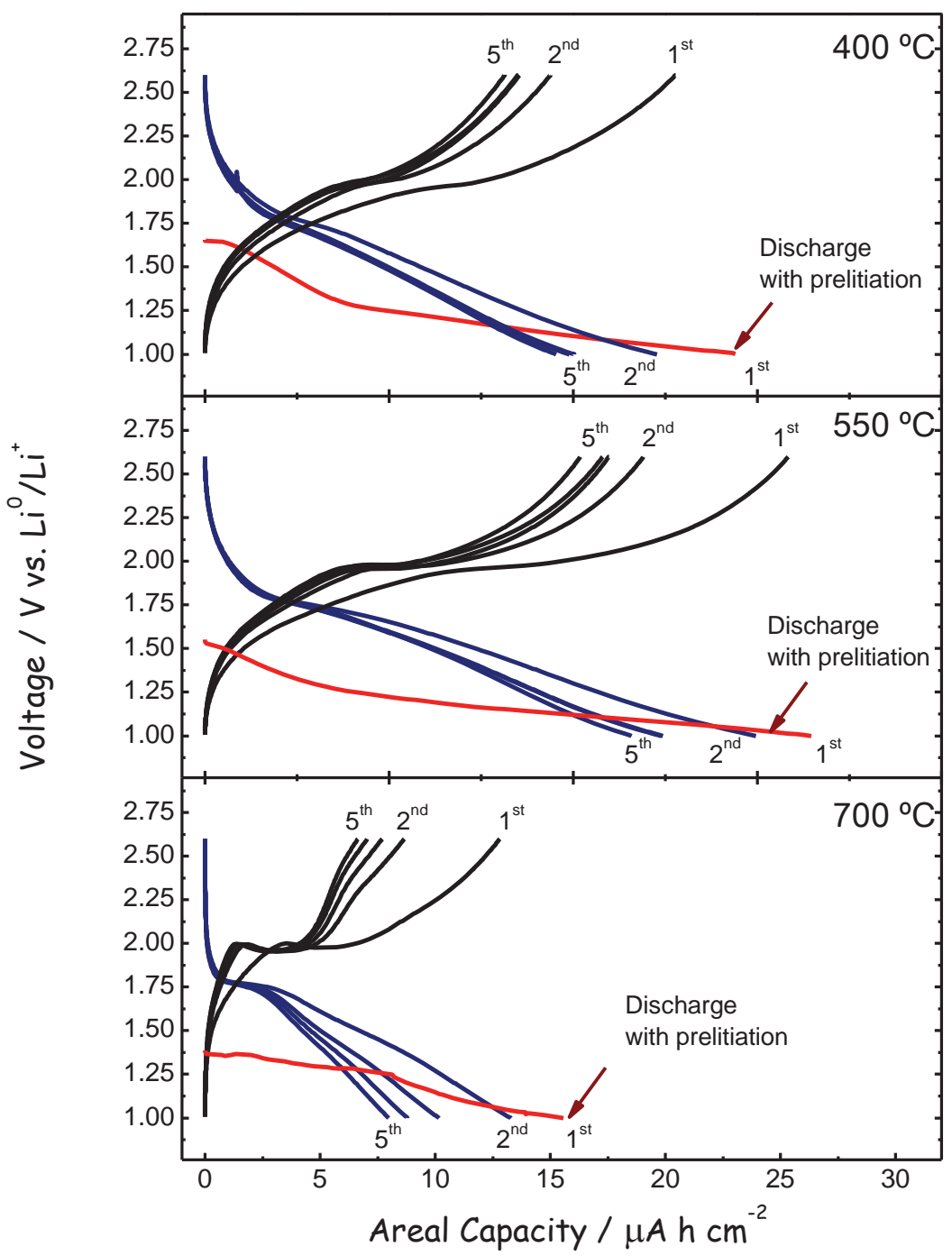

Figure 6. 

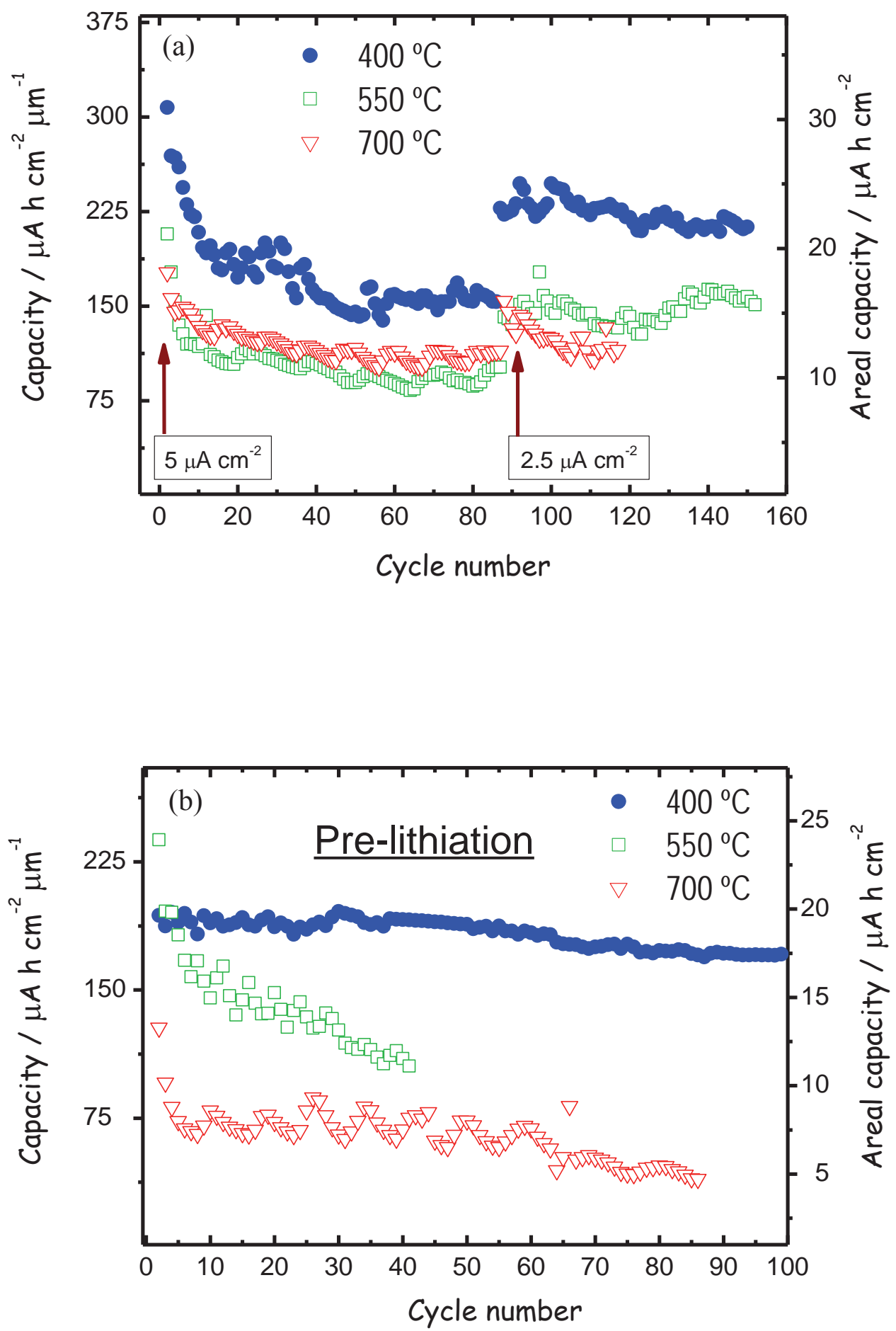

Figure 7. 

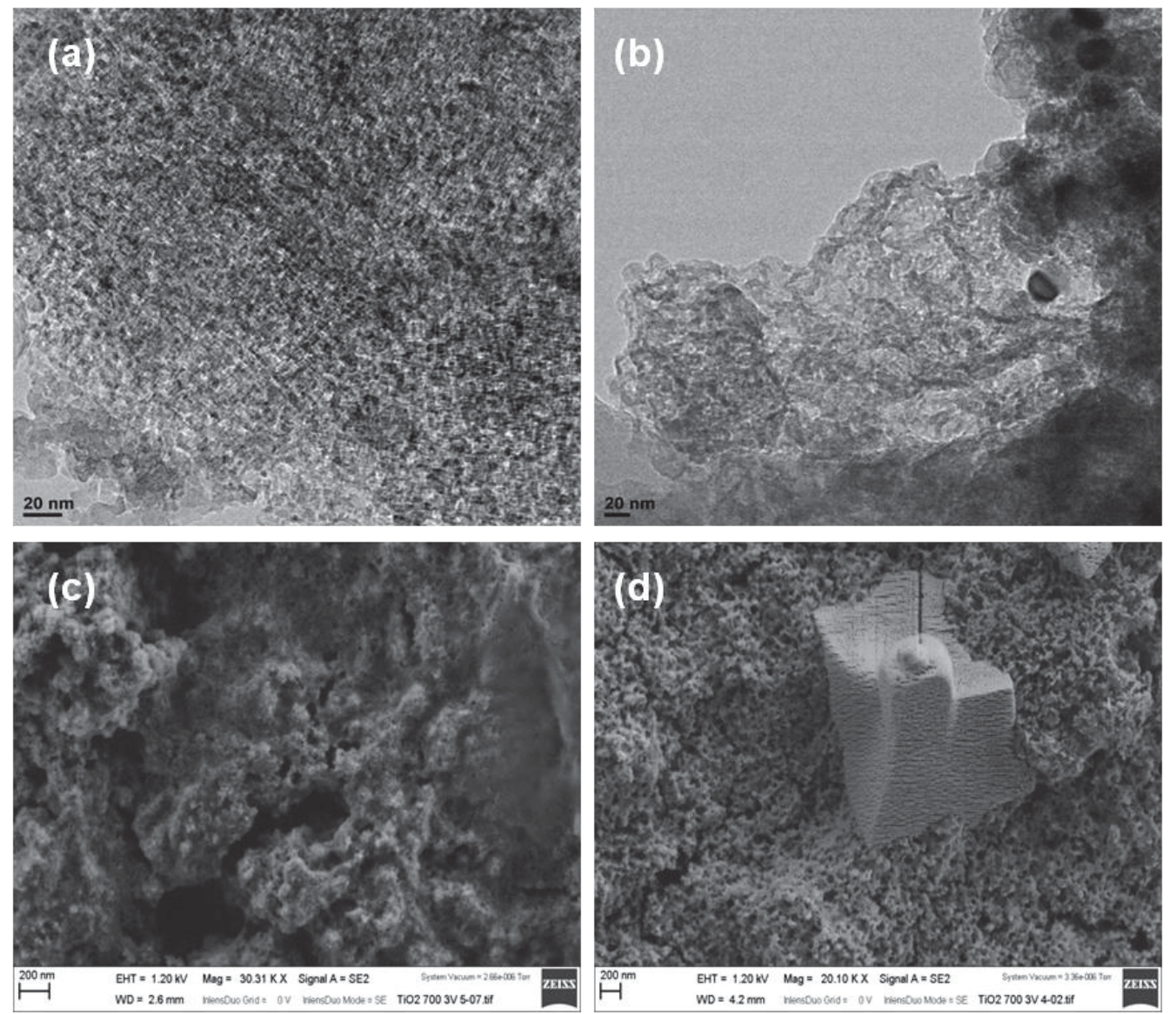

\section{Figure 8.}




\title{
Ordered mesoporous oxide for thin film microbatteries with enhanced lithium storage
}

\author{
Gregorio F. Ortiz ${ }^{* a}$, Ángel Berenguer-Murcia ${ }^{b}$, Marta Cabello ${ }^{a}$, Diego Cazorla-Amorós ${ }^{b}$ \\ and José L. Tirado \\ ${ }^{a}$ Laboratorio de Química Inorgánica, Universidad de Córdoba, Edificio Marie Curie, Campus de \\ Rabanales, 14071 Córdoba, Spain \\ ${ }^{b}$ Instituto Universitario de Materiales, Departamento de Química Inorgánica, Universidad de Alicante, \\ Ap. 99 - 03080 Alicante, Spain
}

*Corresponding author, email: q72maorg@uco.es

Tel. and Fax.: +34 957218637

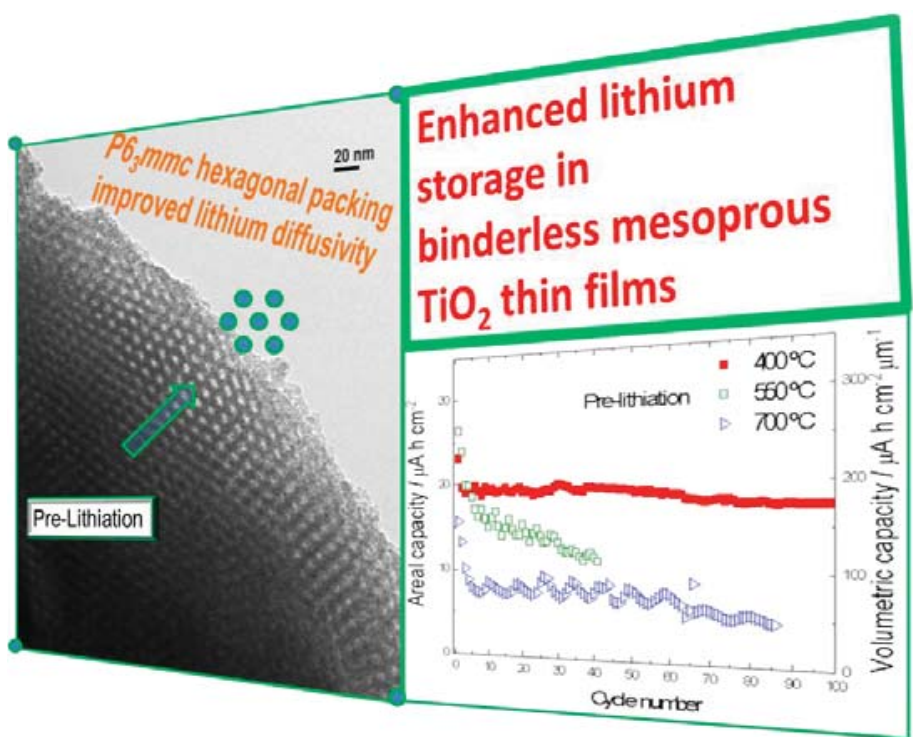




\section{Highlights}

$3 \mathrm{D}$ ordered mesoporous binderless $\mathrm{TiO}_{2}$ electrode exhibited improved $\mathrm{Li}$ storage.

$>$ The hexagonal packing accounts for a better connectivity and lithium diffusivity.

Maximum capacity of $470 \mu \mathrm{A} \mathrm{h} \mathrm{cm} \mathrm{cm}^{-2}$ over 100 cycles is achieved. 